\title{
Maximal exercise response of paraplegic wheelchair road racers
}

\author{
R A Cooper PhD, ${ }^{1} \mathrm{~S}$ M Horvath $\mathrm{PhD},{ }^{2} \mathrm{~J}$ F Bedi PhD,${ }^{2} \mathrm{D}$ M Drechsler-Parks PhD ${ }^{2}$ \\ R E Williams MS ${ }^{2}$ \\ ${ }^{1}$ Biomedical Engineering Program, California State University, Sacramento, California \\ 95819-6019; ${ }^{2}$ Environmental Stress Laboratory, Neuroscience Research Institute, \\ University of California, Santa Barbara, California 93106, USA.
}

The maximal metabolic responses of 11 paraplegic wheelchair road racers were evaluated with 2 wheelchair exercise protocols: increasing speed and increasing resistance. The maximal heart rates, minute ventilations and oxygen uptakes were similar for the 2 tests, indicating that either protocol is suitable for maximal wheelchair dynamometer exercise tests for groups. The resulting data were then compared to published data on maximal arm exercise by athletic and non athletic paraplegics and ambulatory males of the same age group. The combined mean values for both exercise tests of maximal oxygen consumption rate $\left(\mathrm{VO}_{2 \max }=37.4 \mathrm{ml} / \mathrm{kg} / \mathrm{min}\right)$, minute ventilation $\left(\mathrm{V}_{\mathrm{E}}=109.4 \mathrm{l} / \mathrm{min}\right)$, respiratory exchange quotient $\left(\mathrm{RQ}_{\max }=1.18\right)$ and heart rate $(187$ beats $/ \mathrm{min})$ are in the mid range of reported data on wheelchair athletes. The mean RQ and heart rate values were similar to those achieved by ambulatory individuals performing maximal exercise tests. The mean $\mathrm{VO}_{2 \max }$ of $37.4 \mathrm{ml} / \mathrm{kg} / \mathrm{min}$ in our subjects is comparable to that achieved by sedentary ambulatory males of this age group. The data and the comparison to published data suggest several conclusions: in some parameters elite male paraplegic road racers have maximal values similar to those of ambulatory males, and in others they have maximal values substantially lower than might be expected; there is considerable variability among paraplegics in the metabolic responses to maximal exercise, most likely related to differences in cardiovascular fitness; and paraplegics can improve their cardiovascular fitness by training.

Key words: paraplegia; exercise response; wheelchair road racers; body density.

\section{Introduction}

The maximal metabolic responses of ambulatory persons are affected by the exercise protocol employed. ${ }^{1}$ The larger the muscle mass involved in the exercise, the greater the metabolic responses. Thus, arm crank exercise induces smaller increases in the metabolism than cycle ergometer exercise, which induces lesser increases than treadmill exercise. The highest metabolic measurements in ambulatory individuals are obtained with treadmill exercise (running or walking). The potential effect of an evaluative metabolic study can also be influenced by the mass of metabolically active tissue available to the person being tested. Thus, several studies ${ }^{1-13}$ have attempted to evaluate the maximal metabolic responses of paraplegics. These studies used a variety of different exercise protocols, including some with wheelchair ergometers, and some with arm crank ergometers. Multiple protocols have been evaluated in the same subjects only rarely. Thus, the most effective protocol for evaluating maximal exercise responses in paraplegics is unknown.

This study was designed to characterize the metabolic capabilities of a group of male paraplegic wheelchair racers. This report will focus on a comparison of the metabolic responses to 2 wheelchair exercise protocols, and a comparison of the resultant data to the responses of athletic and non athletic paraplegics and ambulatory males of the same age group. 


\section{Methods}

\section{Subjects}

Eleven male paraplegic wheelchair road racers participated in this investigation. Each subject signed an informed consent document outlining the procedures to be followed, and the potential risks and benefits of participation. The protocol and procedures were approved by the UCSB committee on Activities Involving Human Subjects. Except for subject no. 7 who had spina bifida, the subjects were paralyzed due to traumatic spinal cord injury. All subjects were in training for either the June 1989 National Wheelchair Athletic Association (NWAA) Track and Field Championships (Germantown, PA), or the July 1989 NWAA 10-Kilometer Championships (Atlanta, GA). All experiments were completed within 2 months of these competitions.

Each subject was screened by medical history, 12-lead resting electrocardiogram, a battery of clinical pulmonary function tests, and maximal static hand grip strength.

\section{Dynamometer}

The wheelchair dynamometer has been previously described in detail. ${ }^{14}$

\section{Protocol}

Each subject completed all tests on one day, the protocol requiring about 6 hours. The day began with completion of the informed consent procedures and medical history questionnaire. This was followed by a 12-lead electrocardiogram and a series of anthropometric measurements, including height and the length of specific body segments considered possibly relevant to wheelchair racing performance. Measurements were taken with the subject supine. The morning session ended with an exercise test chosen randomly between the exercise protocols.

After a break for lunch the subjects performed duplicate functional residual capacity measurements (FRC). These tests, required for calculation of body density, were performed by a helium dilution method on a water seal spirometer (W E
Collins, Braintree, MA) with the subject seated in his regular wheelchair. The FRC measurements were followed by underwater weighing with the subject lying prone on a nylon mesh cot. The second exercise test followed the underwater weighing. Approximately 3 hours elapsed between the 2 exercise tests.

The subjects were weighed before and after both exercise tests. Subjects removed their shirts, and dried any sweat from the skin prior to measurements. Although nude weights would have been preferable for estimating exercise induced sweat losses, the difficulties these subjects experience in dressing and undressing led to the compromise of removal of only the upper body clothing, and drying of the skin. The sweat related weight losses reported below are thus underestimated.

Once the subject and his racing wheelchair were secured onto the dynamometer, body temperature was taken orally. It was not thought prudent to use rectal thermocouples in these subjects due to their confined position in the racing chairs, and more importantly, due to their lack of sensory perception below the level of their spinal cord injuries. Blood pressure was also measured before each exercise test.

The incremental speed test began at $2.23 \mathrm{~m} / \mathrm{s}$, with added increments of $0.446 \mathrm{~m} / \mathrm{s}$ (13 watts) every 2 minutes until the subject could go no faster. The maximum speed was then maintained to exhaustion.

The incremental resistance test was performed at a constant speed of $2.68 \mathrm{~m} / \mathrm{s}$. The test began with no resistance on the dynamometer, followed by resistance increases of about 10 watts every 90 seconds. The resistance was increased until the subject could no longer maintain the set speed of $2.68 \mathrm{~m} / \mathrm{s}$. The subject continued at the last resistance setting where $2.68 \mathrm{~m} / \mathrm{s}$ could be maintained until volitional exhaustion.

Metabolic data were collected on-line using standard open circuit techniques by an International Business Machine (IBM) computer. The subjects breathed on a two-way Hans Rudolph valve throughout the exercise tests. Inspired ventilation was measured throughout both exercise tests by software 
integration of the flow signal form a Fleisch no. 3 pneumotachometer, the calibration of which was verified with a known volume of air delivered with a $3 \mathrm{~L}$ syringe. Mixed expired gases were sampled from a $3 \mathrm{~L}$ mixing chamber at $10 \mathrm{~Hz}$, and measured for oxygen (Applied Electrochemistry, S3-A) and carbon dioxide (Beckman, LB2), the concentrations of which were averaged over 30 -second epochs. The analyzers were calibrated before and after each exercise test with gases of known $\mathrm{O}_{2}$ and $\mathrm{CO}_{2}$ concentrations. Heart rate was recorded every 30 seconds from a Computer Instruments Corporation heart rate monitor.

Each subject remained on the mouthpiece for 5 minutes following both exercise tests for measurement of metabolic recovery, after which the subject again took his oral temperature. Blood pressure was taken immediately after cessation of exercise.

Three criteria were used to determine $\mathrm{VO}_{2 \max }$ (1) respiratory quotient greater than 1.0 ; (2) heart rate near predicted maximum; and (3) a plateau in oxygen uptake with increased work load.

\section{Statistical analysis}

The metabolic responses to 2 exercise protocols were compared with paired T-tests ${ }^{15}$ to determine whether responses were significantly different $($ alpha $=0.05)$.

\section{Results}

Table I describes the physical characteristics of the subjects, including body density and hand grip strength. Table II describes racing/training histories of the subjects.

Table III contains maximal values for various measured metabolic parameters for each subject and mean values for the subject group. There were no statistically significant $(p>0.05)$ differences between maximal metabolic responses to the 2 exercise protocols.

The mean pre exercise blood pressures were $125 \pm 10 / 78 \pm 4 / 71 \pm 7 \mathrm{mmHg}$ for the resistance test, and $123 \pm 9 / 77 \pm 6 / 70 \pm$ $7 \mathrm{mmHg}$ for the speed test. Immediately following exercise mean blood pressures were $173 \pm 14 / 61 \pm 17 / 18 \pm 17 \mathrm{mmHg}$, and $174 \pm 21 / 52 \pm 21 / 18 \pm 21 \mathrm{mmHg}$ as measured according to American Heart Association Standards for the resistance and speed tests, respectively. Not all measurers of blood pressure are capable of effectively hearing all 3 vessel sounds, and thus can only effectively hear sounds 1 and 3 . There was no difference $(p>0.05)$ between pre or post exercise protocols.

The sweat related weight loss with 2 protocols, $0.59 \pm .79$ and $0.48 \pm .36 \mathrm{~kg}$ for resistance and speed tests respectively, was similar $(p>0.05)$. The subjects lost an average of $0.85 \%$ of body weight due to

Table I Characterization of the subjects

\begin{tabular}{llllcrrr}
\hline $\begin{array}{l}\text { Subject } \\
\text { number }\end{array}$ & $\begin{array}{l}\text { Age } \\
\text { yrs }\end{array}$ & $\begin{array}{c}\text { Injury } \\
\text { level }\end{array}$ & Class* & \multicolumn{2}{c}{$\begin{array}{c}\text { Wt } \\
\mathrm{kg}\end{array}$} & $\begin{array}{c}\text { Body } \\
\text { density }\end{array}$ & \multicolumn{2}{c}{$\begin{array}{c}\text { Handgrip (kg) } \\
\text { Right }\end{array}$} & Left \\
\hline 1 & 28 & T5/6 & II & 71.48 & 1.058 & 56.0 & 44.0 \\
2 & 34 & T4/5 & II & 71.10 & 1.058 & 47.0 & 39.0 \\
3 & 36 & T3/4 & II & 69.30 & 1.062 & 57.5 & 42.0 \\
4 & 41 & T5/6 & II & 72.57 & 1.042 & 44.0 & 39.0 \\
5 & 24 & T3 & II & 60.06 & 1.059 & 46.0 & 39.0 \\
6 & 29 & T9 & III & 54.20 & 1.061 & 44.0 & 42.0 \\
7 & 20 & L1/2+ & IV & 65.18 & 1.027 & 45.0 & 37.5 \\
8 & 30 & T6/7 & III & 62.62 & 1.052 & 44.5 & 34.5 \\
9 & 36 & T10/11 & IV & 74.85 & 1.050 & 44.5 & 41.0 \\
10 & 27 & T12/L1 & IV & 62.35 & 1.053 & 41.0 & 35.5 \\
11 & 35 & T5/6 & II & 61.77 & 1.074 & 47.0 & 32.0 \\
\hline Mean & 30.9 & & & 65.95 & 1.053 & 47.0 & 38.7 \\
SD & \pm 5.8 & & & \pm 6.08 & \pm 0.012 & \pm 4.9 & \pm 3.4 \\
\hline
\end{tabular}

+ This subject has spina bifida

* Each subject was classified by a NWAA certified examiner 
Table II Subject training profiles

\begin{tabular}{lccccc}
\hline $\begin{array}{l}\text { Subject } \\
\text { number }\end{array}$ & $\begin{array}{c}\text { Years } \\
\text { injured }\end{array}$ & $\begin{array}{c}\text { Years } \\
\text { racing }\end{array}$ & $\begin{array}{c}\text { Training } \\
\text { Wheeling } \\
\text { (hr/week) }\end{array}$ & $\begin{array}{c}10 \mathrm{~K} \text { time* } \\
\text { Weights } \\
\text { (hr/week) }\end{array}$ & \\
\hline 1 & 11 & 7 & 3.0 & 6.0 & $30: 30$ \\
2 & 10 & 9 & 2.5 & 2.5 & $29: 00$ \\
3 & 3 & 1.5 & 6.8 & 2.3 & $27: 04$ \\
4 & 22 & 5 & 6.3 & 2.6 & $25: 00$ \\
5 & 3 & 3 & 4.7 & 8.0 & $25: 03$ \\
6 & 9 & 5 & 5.0 & 2.0 & $27: 36$ \\
7 & $20^{+}$ & 5 & 5.0 & 3.0 & $32: 40$ \\
8 & 11 & 5 & 7.5 & 2.3 & $26: 22$ \\
9 & 2 & 0.5 & 5.0 & 0.0 & $29: 05$ \\
10 & 9 & 2 & 4.0 & 3.0 & $29: 30$ \\
11 & 9 & 8 & 5.0 & 0.0 & 24.03 \\
\hline Mean & 9.9 & 4.6 & 5.0 & 2.9 & $27: 30$ \\
SD & \pm 6.1 & \pm 2.6 & \pm 1.4 & \pm 2.2 & $\pm 2: 50$ \\
\hline
\end{tabular}

* Best time within one month of experiments

+ This subject has spina bifida

sweating during exercise test. However, sweat related weight loss subject 4 was equivalent to $4.22 \%$ of his body weight during the resistance test, and in subject 10 was equivalent to $2.44 \%$ of his body weight during the speed test.

Table IV compares our results to those of other studies on athletic paraplegics and on ambulatory males performing maximal arm exercise.

\section{Discussion}

The lack of any significant differences between the maximal metabolic measurements from the 2 exercise protocols indicates that both are appropriate for maximal wheelchair exercise testing of groups of paraplegics. However, there is some individual variability among test protocols. That is, subject no. 3 had a $0.84 \mathrm{l} / \mathrm{min}(37 \%)$ higher maximal oxygen uptake in the resistance test, while subject no. 8 had a $0.80 \mathrm{l} / \mathrm{min}$ $(40 \%)$ higher value on the speed test. This suggests that the 2 test protocols are equivalent in studying groups of paraplegic athletes, but not necessarily for the determination of a single subject's maximal uptake. The combined mean values for both exercise tests for $\mathrm{VO}_{2 \max }(37.4 \mathrm{ml} / \mathrm{kg} / \mathrm{min}), \mathrm{V}_{\mathrm{E}}$ $(109.4 \mathrm{l} / \mathrm{min}), \mathrm{RQ}_{\max }(1.18)$ and heart rate
( 187 beats $/ \mathrm{min}$ ) are in the mid range of reported data on wheelchair athletes (Table IV). The mean RQ and heart rate values were similar ${ }^{1}$ to those achieved by ambulatory individuals performing maximal exercise tests (Table IV).

The mean $\mathrm{VO}_{2 \max }$ of $37.4 \mathrm{ml} / \mathrm{kg} / \mathrm{min}$ in our subjects is comparable to that achieved by sedentary ambulatory males of this age group. ${ }^{1}$ These lower values for $\mathrm{VO}_{2 \max }$ compared to elite ambulatory athletes may be related to several factors. First, arm exercise in ambulatory persons typically induces a $\mathrm{VO}_{2 \max }$ of about $70 \%$ of that achieved with a treadmill test. ${ }^{1}$ If the $70 \%$ ratio is also applicable to paraplegic wheelchair athletes (who have considerable use of their shoulder muscles), our subjects may actually have a $\mathrm{VO}_{2 \max }$ of approximately $3.56 \mathrm{l} / \mathrm{min}$ (compared to the measured $2.49 \mathrm{l} / \mathrm{min}$ ), not exceptional for ambulatory males of this age group. Top ambulatory track athletes of this age group would typically have a $\mathrm{VO}_{2 \max }$ of over $6 \mathrm{l} / \mathrm{min}$.

O'Toole et $a l^{16}$ have reported that ambulatory triathletes achieved a $\mathrm{VO}_{2 \max }$ of $3.65 \mathrm{l} / \mathrm{min}$ during arm crank exercise. The triathalon includes a one mile ocean swim, and thus the training for this swim would be designed to develop considerable arm and shoulder strength and endurance. This de- 
Table III Wheelchair racers maximal test values

\begin{tabular}{|c|c|c|c|c|c|c|c|c|c|c|c|c|}
\hline \multirow[t]{2}{*}{$\begin{array}{l}\text { Subject } \\
\text { number }\end{array}$} & \multicolumn{2}{|c|}{$\begin{array}{c}\mathrm{VO}_{2 \max }{ }^{*} \\
(\mathrm{l} / \mathrm{min})\end{array}$} & \multicolumn{2}{|c|}{$\begin{array}{c}\mathrm{VO}_{2 \max }{ }^{*} \\
(\mathrm{ml} / \mathrm{kg} / \mathrm{min})\end{array}$} & \multicolumn{2}{|c|}{$\begin{array}{c}\mathrm{V}_{\mathrm{Emax}} * \\
(\mathrm{l} / \mathrm{min})\end{array}$} & \multicolumn{2}{|c|}{$\mathrm{RQ}^{*}$} & \multicolumn{2}{|c|}{$\begin{array}{c}\mathrm{F}_{\mathrm{R}}{ }^{*} \\
\text { (breaths/min) }\end{array}$} & \multicolumn{2}{|c|}{$\begin{array}{c}\mathrm{F}_{\mathrm{C}}{ }^{*} \\
\text { (beats/min) }\end{array}$} \\
\hline & Resist & Speed & Resist & Speed & Resist & Speed & Resist & Speed & Resist & Speed & Resist & Speed \\
\hline 1 & 2.88 & 2.76 & 40.4 & 38.3 & 91.2 & 101.1 & 0.960 & 1.138 & $\mathrm{~N} / \mathrm{A}$ & $\mathrm{N} / \mathrm{A}$ & 191 & 190 \\
\hline 2 & 2.24 & 2.12 & 31.2 & 29.8 & 74.0 & 72.1 & 1.041 & 1.131 & 38 & 40 & 176 & 174 \\
\hline 3 & 3.10 & 2.26 & 44.6 & 32.9 & 101.4 & 66.5 & 1.003 & 1.018 & 50 & 38 & 182 & 162 \\
\hline 4 & 2.48 & 2.66 & 34.3 & 36.6 & 99.1 & 103.9 & 1.153 & 1.172 & 50 & 50 & 173 & 183 \\
\hline 5 & 2.60 & 2.64 & 43.4 & 44.0 & 104.7 & 112.1 & 1.320 & 1.155 & 70 & 62 & 189 & 195 \\
\hline 6 & 2.10 & 2.26 & 38.5 & 41.8 & 98.5 & 94.4 & 1.177 & 1.191 & 60 & 62 & 187 & 189 \\
\hline 7 & 2.32 & 2.54 & 35.6 & 39.0 & 112.5 & 121.9 & 1.359 & 1.230 & 56 & 52 & 198 & 204 \\
\hline 8 & 2.00 & 2.80 & 32.0 & 45.3 & 71.7 & 116.6 & 1.074 & 1.265 & 62 & 56 & 176 & 188 \\
\hline 9 & 2.58 & 2.74 & 34.5 & 36.7 & 111.1 & 129.1 & 1.238 & 1.255 & 46 & 58 & 186 & 191 \\
\hline 10 & 2.54 & 2.32 & 40.8 & 37.3 & 154.6 & 144.2 & 1.330 & 1.375 & 66 & 70 & 181 & 186 \\
\hline 11 & 1.84 & 2.30 & 29.6 & 36.9 & 78.6 & 138.0 & 1.175 & 1.265 & 56 & 80 & 175 & 178 \\
\hline Mean & 2.43 & 2.49 & 36.8 & 38.1 & 109.6 & 109.1 & 1.166 & 1.200 & 55 & 57 & 187 & 186 \\
\hline SD & +.36 & +.23 & +4.8 & +4.3 & +19.1 & +23.7 & +.130 & +.089 & +9 & +12 & +9 & +11 \\
\hline
\end{tabular}

* = No significant difference between two tests $(\alpha=0.05)$

$F_{R}=$ Respiratory frequency

$\mathrm{F}_{\mathrm{C}}=$ Cardiac frequency 
Table IV Comparison of metabolic data of subjects performing arm exercise (mean values)

\begin{tabular}{|c|c|c|c|c|c|c|c|}
\hline Reference & $\mathrm{N}$ & $\begin{array}{l}\text { Heart rate } \\
\text { (beats/min) }\end{array}$ & $\begin{array}{l}\mathrm{VO}_{2 \max } \\
(\mathrm{l} / \mathrm{min})\end{array}$ & $\begin{array}{c}\mathrm{VO}_{2 \max } \\
(\mathrm{ml} / \mathrm{kg} / \mathrm{min})\end{array}$ & $\begin{array}{c}\mathrm{V}_{\mathrm{E}} \\
(\mathrm{l} / \mathrm{min})\end{array}$ & RQ & Comments \\
\hline \multicolumn{8}{|c|}{ Paraplegic athletes } \\
\hline 23(a) & 16 & 176 & 1.84 & 27.0 & 84.7 & N/A & 1976 Olympics for \\
\hline (b) & & 177 & 1.87 & 27.3 & 86.3 & N/A & $\begin{array}{l}\text { physically disabled } \\
\text { participants }\end{array}$ \\
\hline 14(a) & 10 & 193 & 1.95 & N/A & 66.8 & N/A & $\begin{array}{l}\text { Not specified } \\
5 \text { Intl. competitors }\end{array}$ \\
\hline $9(a)$ & 16 & 179 & 2.04 & 32.1 & 60.7 & N/A & $\begin{array}{l}\text { Intl. class } \\
\text { sprinters/field } \\
\text { events }\end{array}$ \\
\hline $6(b)$ & 15 & 182 & 2.24 & 34.1 & 105.6 & 1.11 & $\begin{array}{l}\text { Basketball/swim/wt. } \\
\text { lifting - provincial \& } \\
\text { nationally ranked }\end{array}$ \\
\hline 24(b) & 11 & 183 & 2.07 & 36.0 & 78.5 & N/A & $\begin{array}{l}\text { Intl. class basketball/ } \\
\text { swim/javelin }\end{array}$ \\
\hline$*$ & 11 & 186 & 2.49 & 37.4 & 109.1 & 1.20 & Road racers - intl. class \\
\hline $22(b)$ & 7 & 178 & 2.60 & 42.3 & 66.8 & N/A & Elite road racers \\
\hline $20(a)$ & 3 & N/A & 2.80 & 45.7 & N/A & N/A & $\begin{array}{l}\text { Intl. class, } \\
\text { sport not specified }\end{array}$ \\
\hline
\end{tabular}

Non athletic paraplegics

\begin{tabular}{|c|c|c|c|c|c|c|c|}
\hline 24(b) & 9 & 174 & 1.38 & 19.6 & 56.5 & N/A & \\
\hline $21(\mathrm{~b})$ & 8 & 160 & 1.50 & 24.9 & 68.7 & 1.14 & \\
\hline 6(b) & 15 & 183 & 1.56 & 25.2 & 68.8 & 1.16 & \\
\hline \multirow[t]{2}{*}{ 17(b) } & 7 & 181 & 1.88 & 25.4 & N/A & 1.14 & Pre training \\
\hline & & 178 & 2.07 & 28.0 & N/A & 1.21 & Post training \\
\hline 12(b) & 9 & 179 & 1.47 & 27.0 & N/A & N/A & \\
\hline $5(a)$ & 10 & 181 & 1.94 & 27.1 & 79.7 & N/A & \\
\hline $8(\mathrm{a})$ & 10 & 187 & 2.21 & 33.8 & 81.1 & $\mathrm{~N} / \mathrm{A}$ & \\
\hline (b) & & 181 & 1.96 & 30.0 & 66.4 & N/A & \\
\hline \multirow{2}{*}{$\begin{array}{r}19 \text { (a) } \\
\text { (b) }\end{array}$} & 8 & 180 & N/A & 33.4 & 71.9 & N/A & \\
\hline & & 176 & N/A & 31.2 & 69.6 & $\mathrm{~N} / \mathrm{A}$ & \\
\hline \multicolumn{8}{|c|}{ Ambulatory males } \\
\hline 24(b) & 8 & 182 & 1.77 & 25.8 & 76.3 & N/A & \\
\hline 21(b) & 11 & 168 & 2.1 & 29.5 & 84.0 & N/A & \\
\hline 2(b) & 59 & 173 & 2.35 & 34.6 & 86.2 & N/A & \\
\hline 24(b) & 13 & 168 & 3.00 & 38.1 & 104.6 & N/A & \\
\hline $15(c)$ & 12 & 178 & 2.87 & 40.4 & 116.0 & 1.25 & \\
\hline 18(b) & 8 & 176 & 3.65 & 49.1 & 134.9 & N/A & \\
\hline
\end{tabular}

$\mathrm{a}=$ wheelchair exercise $\mathrm{b}=$ arm crank exercise; $\mathrm{c}=$ tethered surfboard paddling; ${ }^{*}=$ present study data

gree of training was reflected in the higher $\mathrm{VO}_{2}$ values achieved by these triathletes. It should be noted that these triathletes were tested on an arm crank ergometer. The continuous nature of arm cranking versus wheelchair propulsion, along with the potentially larger involved muscle mass of the triathletes, may have contributed to the higher maximal arm exercise values obtained on these triathletes.

Second, wheelchair racing likely depends on strength and technique at least as much as it does on a high oxygen uptake capacity. Once the athlete has the wheelchair moving, 
there are prolonged glide periods between arm strokes. Upper body strength and endurance are required to make adequate arm strokes to maintain chair momentum. The difference in arm/shoulder action may explain the higher $\mathrm{VO}_{2 \max }$ measured by O'Toole et al ${ }^{16}$ in triathletes performing arm crank exercise compared to measurements on wheelchair propulsion. Arm crank exercise differs considerably from exercise tests in which wheelchairs are propelled, although several studies have compared the maximal metabolic responses of paraplegics to wheelchair ergometry and arm crank ergometry and obtained similar results. ${ }^{4,9,12}$ However, given the physical limitations of paraplegics, it is difficult to conceive of an alternative test which might be more suitable than a wheelchair test. In any case, the $\mathrm{VO}_{2 \max }$ achieved during a racing wheelchair ergometry test is the one most relevant to wheelchair racing.

Third, these subjects, though among the United States' elite wheelchair racers, did not train to the extent of elite ambulatory athletes. On average, our subjects trained slightly over one hour per day. Most elite ambulatory athletes would train at least 3-4 hours per day. Some previous research on non athlete paraplegics indicates that our subjects had relative high values for $\mathrm{VO}_{2 \max }$, compared to less active paraplegics, although the 2 groups of paraplegics overlap considerably (Table IV). This suggests that there is a wide range of aerobic capacity among paraplegics, and further that paraplegics can improve their cardiovascular fitness through training of the type employed by our subjects. ${ }^{8,13}$ In contrast, Hooker and Wells ${ }^{17}$ reported on paraplegics who participated in 8-week wheelchair exercise training programs of low or moderate intensity. There was no improvement in cardiovascular fitness with either protocol. The training consisted of 320 -minute bouts of exercise per week. This training schedule would be insufficient to induce a training effect in ambulatory subjects, and it is unclear on what grounds the authors anticipated an improvement in their subjects. The American College of Sports Medicine (ACSM) training guidelines as typically applied only induce a training effect in people who are quite unfit to start with, and will eventually lead to a plateau in level of fitness which cannot be exceeded unless intensity and/or frequency of training is increased. Three 20-minute bouts of low or moderate intensity exercise per week would do little or nothing in people who are moderately fit. The training program studied by Hooker and Wells was of such moderate intensity that it was within baseline capabilities of the subjects, and thus induced no improvement. Not only this, the ACSM guidelines were designed to develop and maintain what is considered by ACSM to be the minimum level of physical fitness commensurate with health. The fact that some paraplegics described as athletes have higher maximal values for $\mathrm{VO}_{2}$ and $\mathrm{V}_{\mathrm{E}}$ suggests that paraplegics can significantly improve their cardiovascular fitness by regular training. Comparison of the $\mathrm{VO}_{2 \max }$ values of paraplegic male athletes and ambulatory males (in $\mathrm{ml} / \mathrm{kg}$ to account for body weight differences) indicates that there is a wide range of $\mathrm{VO}_{2 \max }$ values among paraplegic athletes, suggesting that at least those on the low end of the scale have not reached their potentials (Table IV). Further, our subjects had good shoulder girdle use. According to Table IV, the highest literature values for $\mathrm{VO}_{2 \max }$ in $\mathrm{ml} / \mathrm{kg}$ for paraplegic athletes was between those of the 2 highest values on arm crank exercise in ambulatory males. This all together suggests that many paraplegics with good shoulder girdle use probably have not reached their full aerobic potential.

Grip strength in the right and left hands were similar to values obtained on ambulatory males, and are lower than those reported on paraplegics by Wicks et al. ${ }^{12}$ The difference in grip strength between the right and left hands was comparable to that typically observed between the dominant and non dominant hands. All of the subjects were right handed. This suggests that handgrip strength is not a major factor in wheelchair racing among paraplegic males, and further suggests that arm and shoulder girdle strength play a greater role.

The mean body density $(1.053 \pm 0.012)$, although within the range of ambulatory males in this age group, ${ }^{1}$ is higher than 
expected for endurance athletes. Inability to use the leg and trunk muscles leads to muscle atrophy, and can lead to replacement of muscle by fat in paraplegics. Thus, the subjects' appearance of relative leanness can be misleading. Bone and mineral density, tissue distribution and effects of immersion and body position on functional residual capacity are all sources of error in the usual equations for calculation of body density and percent body fat. Although it is clear that long term paralysis leads to extensive changes in tissue distribution and bone mineralization, to our knowledge, no investigations have been published which provide a comparison of these parameters in paraplegic and ambulatory subjects. Thus, application of the usual assumptions for calculation of body density and percent body fat by hydrostatic weighing to paraplegics is based on even shakier grounds than with ambulatory subjects. George et $a l^{6,18}$ have reported on hydrostatic weighing in spinal injured subjects. It is clear from their results that the usual assumptions inherent in calculation of both body density and percent body fat are inappropriate for use with paraplegics. George et al ${ }^{18}$ compared the fat free mass of ambulatory and spinal injured subjects as calculated by hydrodensiometry and by total body water. The 2 methods had a 0.951 correlation coefficient for the ambulatory subjects, compared to a correlation coefficient of 0.705 for the spinal injured subjects. This difference suggests that the body compartments (ie water, fat, mineral, muscle) are different for the 2 groups of subjects, and indicates that the usual equations for calculation of body density and percent body fat are not appropriate for use in paraplegics. Lussier et al ${ }^{19}$ compared percent body fat calculated from whole body potassium and hydrodensiometry in 2 women wheelchair athletes. The 2 methods yielded similar results. However, since no equations specifically developed for use with paraplegics are available, we have reported body density of our subjects, and calculated the mean percent body body fat $(19.4 \pm 4.8 \%)$ by the Brozek ${ }^{20}$ equation, as estimates only, subject to the caveats outlined above. Our mean body density is similar to that reported by George et al $l^{6,18}$ on non athletic paraplegics. The estimated percent body fat is similar to that reported for athletic and non athletic paraplegics by Zwiren and Bar-Or, ${ }^{13}$ and lower than that reported by George et al. . $^{6,18}$

The resting blood pressure measurements were within normal limits, although the pressures measured immediately after exercise were lower than typically measured in ambulatory people who have performed maximal exercise tests. The mean sweat related weight losses with these 2 exercise protocols are small compared to those observed in ambulatory subjects, confirming that paraplegics have a reduced ability to sweat below the level of their spinal cord injury. However, the greater sweat losses of subjects 4 and 10 suggest that there are some individual differences in sweating ability, and may indicate that training can improve the capacity for sweating in paraplegics.

Further study is required to determine the extent to which upper body strength, technique, and endurance play a role in wheelchair racing performance. Our results suggest that strength, technique and endurance are all relevant to wheelchair racing performance. As wheelchair racing is still developing and athletes are learning more about the sport and how to train more effectively, paraplegic wheelchair racers have probably not yet attained their maximal potential.

Several conclusions may be drawn from our study. First, either increasing speed or increasing resistance protocols are suitable for maximal wheelchair exercise testing in paraplegics. Second, in some metabolic parameters elite male paraplegic wheelchair racers have maximal values similar to ambulatory athletes, and in other parameters they have maximal values lower than might be expected. Third, there is considerable variability in the metabolic responses to maximal exercise in paraplegics, most likely related to differences in cardiovascular fitness by training.

\section{Acknowledgements}

The authors gratefully acknowledge the technical assistance of Dorothy L Batterton, and the voluntary participation of the subjects, with- 
out whose enthusiastic participation this study could not have been completed. This study was supported in part by operating funds of the
Environmental Stress Laboratory, and a gift from the Far West Wheelchair Athletic Association.

\section{References}

1 Astrand PO and Rodahl K (1970) Textbook of Work Physiology. McGraw Hill Book Co, New York.

2 Coutts KD, Rhodes EC, McKenzie DC (1983) Maximal exercise responses of tetraplegics and paraplegics. $J$ Appl Physiol 55: 479-482.

3 Davies GM, Shephard RJ (1988) Cardiorespiratory fitness in highly active versus inactive paraplegics. Med Sci Sports Ex 20: 463-468.

4 Gass GC, Camp EM (1984) The maximum physiological responses during incremental wheelchair and arm cranking exercise in male paraplegics. Med Sci Sports Ex 16: 355-359.

5 Gass GC, Camp EM (1979) Physiological characteristics of trained Australian paraplegic and tetraplegic subjects. Med Sci Sports Ex 11: 256-259.

6 George CM, Wells CL, Dugan CL, Hardison R (1987) Hydrostatic weights of patients with spinal injury: reliability of measurements in standard sit-in and Hubbard tanks. Phys Therapy 67: 921-925.

7 Lakomy HKA, Campbell I, Williams C (1987) Treadmill performance and selected physiological characteristics of wheelchair athletes. Brit J Sports Med 21: 130-133.

8 Nilsson S, Staff PH, Pruett EDR (1975) Physical work capacity and the effect of training on subjects with long-standing paraplegia. Scand J Rehabil Med 7: 51-56.

9 Pitetti KH, Snell PG, Stray-Gundersen J (1987) Maximal response of wheelchair-confined subjects to four types of arm exercise. Arch Phys Med Rehabil 68: 10-13.

10 Sanderson DJ, Sommer HJ (1985) Kinematic features of wheelchair propulsion. J Biomech 18: 423-429.

11 Wells CL, Hooker SP, Williams TJ (1988) Aerobic capacity of elite paraplegic road racers. Med Sci Sports Ex 20 (suppl 27) 20 (2): 527.

12 Wicks JR, Oldrige, NB, Cameron BJ, Jones NL (1983) Arm cranking and wheelchair ergometry in elite spinal cord-injured athletes. Med Sci Sports Ex 15: 224-231.

13 Zwiren LD, Bar-Or O (1975) Responses to exercise of paraplegics who differ in conditioning level. Med Sci Sports Ex 7: 94-98.

14 Cooper RA (1990) A force/energy optimization model for wheelchair athletics. IEEE Transactions on Systems, Man and Cybernetics 20(2): 444-449.

15 Devore JL (1982) Probability and Statistics for Engineering and the Sciences. Brooks/Cole Publishing Company, Monterey, CA. Pgs. 278-316.

16 O'Toole ML, Douglas W, Hiller B, Crosby LO, Douglas PS (1987) The ultra-endurance triathlete: a physiological profile. Med Sci Sports Ex 19: 45-50.

17 Hooker SP, Wells CL (1989) Effects of low and moderate-intensity training in spinal cord-injured persons. Med Sci Sports Ex 21: 18-22.

18 George CM, Wells CL, Dugan NL (1988) Validity of hydrodensiometry for determination of body composition in spinal injured subjects. Human Biol 60: 771-780.

19 Lussier L, Knight J, Bell G, Lohman T, Morris AF (1983) Body composition in two elite female wheelchair athletes. Paraplegia. 21: 16-22.

20 Brozek JFG, Andersen JT, Keys A (1973) Densiometric analysis of body composition: revision of some quantitative assumptions. Ann NY Acad Sci 110: 113-140. 